\title{
Amyotrophic Lateral Sclerosis Genetic Access Program
}

Paving the Way for Genetic Characterization of ALS in the Clinic

Jennifer Roggenbuck, MS, CGC, Kelly A. Rich, MS, CGC, Leah Vicini, MS, CGC, Marilly Palettas, MPH, Joceyln Schroeder, BS, Christina Zaleski, MS, CGC, Tara Lincoln, MLIS, Luke Drury, PhD, and Jonathan D. Glass, MD

Neurol Genet 2021;7:e615. doi:10.1212/NXG.0000000000000615

\author{
Correspondence \\ Jennifer Roggenbuck \\ jennifer.roggenbuck@osumc.edu
}

\section{Abstract}

\section{Objective}

To report the frequency of amyotrophic lateral sclerosis (ALS) genetic variants in a nationwide cohort of clinic-based patients with ALS with a family history of ALS (fALS), dementia (dALS), or both ALS and dementia (fALS/dALS).

\section{Methods}

A multicenter, prospective cohort of 573 patients with fALS, dALS, or fALS/dALS, underwent genetic testing in the ALS Genetic Access Program (ALS GAP), a clinical program for clinics of the Northeast ALS Consortium. Patients with dALS underwent C9orf72 hexanucleotide repeat expansion (HRE) testing; those with fALS or fALS/dALS underwent C9orf72 HRE testing, followed by sequencing of SOD1, FUS, TARDBP, TBK1, and VCP.

\section{Results}

A pathogenic (P) or likely pathogenic (LP) variant was identified in 171/573 (30\%) of program participants. About half of patients with fALS or fALS/dALS (138/301, 45.8\%) had either a C9orf72 HRE or a P or LP variant identified in SOD1, FUS, TARDBP, TBK1, or VCP. The use of a targeted, 5-gene sequencing panel resulted in far fewer uncertain test outcomes in familial cases compared with larger panels used in other in clinic-based cohorts. Among dALS cases $11.8 \%(32 / 270)$ were found to have the C9orf72 HRE. Patients of non-Caucasian geoancestry were less likely to test positive for the C9orf72 HRE, but were more likely to test positive on panel testing, compared with those of Caucasian ancestry.

\section{Conclusions}

The ALS GAP program provided a genetic diagnosis to $\sim 1$ in 3 participants and may serve as a model for clinical genetic testing in ALS.

\footnotetext{
From the Department of Internal Medicine (J.R.) and Department of Neurology (J.R., K.A.R.), The Ohio State University Wexner Medical Center, Columbus; The Ohio State University Wexner Medical Center (L.V.), College of Medicine, Columbus; Department of Biomedical Informatics (M.P.), The Ohio State University, Center for Biostatistics, Columbus; PreventionGenetics, LLC (J.S., C.Z., T.L., L.D.), Marshfield, Wl; The Northeast ALS Consortium (NEALS) (T.L.); and Emory ALS Center (J.D.G.), Emory University School of Medicine, Atlanta, GA. 


\section{Glossary}

ACMG = American College of Medical Genetics; ALS = amyotrophic lateral sclerosis; dALS = patients with a family history of dementia; fALS = patients with a family history of ALS; fALS/dALS = patients with a family history of both ALS and dementia; FDR = first-degree relative; FTD = frontotemporal dementia; GAP = Genetic Access Program; HRE = hexanucleotide repeat expansion; $\mathbf{L P}=$ likely pathogenic; $\mathbf{O R}=$ odds ratio; $\mathbf{P}=$ pathogenic; $\mathbf{S D R}=$ second-degree relative; $\mathbf{T D R}=$ third-degree relative; VUS = variant of uncertain significance.

The 2011 discovery of the pathogenic hexanucleotide repeat expansion (HRE) in C9orf72 and development of commercial HRE assays empowered amyotrophic lateral sclerosis (ALS) clinicians to provide a genetic diagnosis for half of familial and $10 \%$ of sporadic cases of ALS. However, 10 years later, many persons with ALS still do not have access to this and other genetic tests for ALS. Although European guidelines for ALS genetic testing have been developed, ${ }^{1,2}$ current US consensus management guidelines do not address the issue of genetic testing, and uncertainties persist regarding whom to test, appropriate testing algorithms, access to genetic counseling, and cost. ${ }^{3}$ These challenges have contributed to inconsistent testing practices and present barriers to the genetic characterization of clinic populations. As gene-targeted therapies move through the preclinical and clinical trial pipeline, there is a pressing need to improve the practice of genetic testing, determine the incidence of genetic forms of ALS in clinicbased populations, and identify appropriate candidates for clinical trials.

The ALS Genetic Access Program (ALS GAP) was designed as a pilot genetic testing and counseling program for clinicians of the Northeast ALS Consortium (neals.org). A targeted testing algorithm guided by family history criteria was applied for 573 patients with ALS from NEALS clinics nationwide, representing the largest clinical ALS cohort reported to undergo clinical genetic testing using standard commercial testing and American College of Medical Genetics (ACMG) interpretation criteria. ${ }^{4}$ The cost of genetic testing and counseling was funded by advocacy and industry donors.

\section{Methods}

\section{Program Population}

Patients who presented to NEALS clinics and had a diagnosis of definite or probable ALS per El-Escorial criteria were offered ALS genetic testing using a testing algorithm based on family history over an 18-month period (January 2019 to June 2020; Figure 1). Program participation is free of cost, and ordering clinicians are encouraged to prioritize patients with limited resources for obtaining testing and counseling. This program continues to enroll patients.

Optional pre- and/or post-test genetic counseling was available via a telemedicine service staffed by board-certified, licensed genetic counselors. Eligible patients either were diagnosed with ALS alone or with concomitant frontotemporal dementia
(FTD). Any family history of ALS (fALS), family history of dementia (dALS), or family history of both (fALS/dALS) was recorded for each patient, and the degree of relationship of these relatives (first-degree relative [FDR], second-degree relative $[\mathrm{SDR}]$, and third-degree relative $[\mathrm{TDR}]$ ) was noted on the test requisition form. No attempt was made to differentiate FTD from other dementias in the recorded family history due to unreliability of reported dementia diagnoses in family histories. ${ }^{3,5}$ Data were collected on patient demographics, clinical presentation, age at onset, geoancestry, and testing outcomes. Ordering clinicians were responsible for obtaining informed consent for genetic testing. The Institutional Review Board of the Ohio State University Wexner Medical Center designated this project as exempt from review.

\section{Genetic Testing}

All qualifying patients with ALS or ALS/FTD who accepted testing $(\mathrm{n}=573)$ underwent C9orf72 HRE testing as a first step. This was performed using a combination of 2 repeatprimed PCR and 2 fluorescent amplicon length analysis $(>30$ repeats considered pathogenic, 25-29 repeats considered intermediate, and $<25$ repeats considered normal). Patients with fALS or fALS/dALS who tested negative for the HRE were then tested via next-generation sequencing for 5 ALS genes: SOD1, FUS, TARDBP, TBK1, and VCP, selected for their high penetrance and frequency ( $1 \%$ or more) in familial ALS cohorts. ${ }^{6,7}$ Patients with dALS did not undergo panel testing. Sequencing was performed using Illumina NovaSeq 6000 , with $>96 \%$ of targeted regions covered at a depth of 20x. Reads were aligned to a reference sequence (hg19), and sequence changes were identified and interpreted. In this study, a positive result was defined as identifying a pathogenic C9orf72 HRE or a pathogenic (P) or likely pathogenic (LP) variant, per ACMG variant classification criteria, on targeted panel testing. We were unable to determine how many patients with ALS declined testing when offered.

\section{Family History Quantification}

Family history scores were assigned for all patients in our cohort. The degree of ALS family history was quantified based on the number and degree (FDR, SDR, and TDR) of affected family members with ALS, as reported by the ordering clinician. This scoring system was adapted from a previously reported approach. ${ }^{8}$ Cumulative scores were assigned in the following manner: 1 affected FDR $=3$; multiple affected FDR $=6 ; 1$ affected $\mathrm{SDR}=2$; multiple affected $\mathrm{SDR}=4 ; 1$ affected $\mathrm{TDR}=1 ; 1$ affected FDR and 1 affected SDR $=5$; and 1 


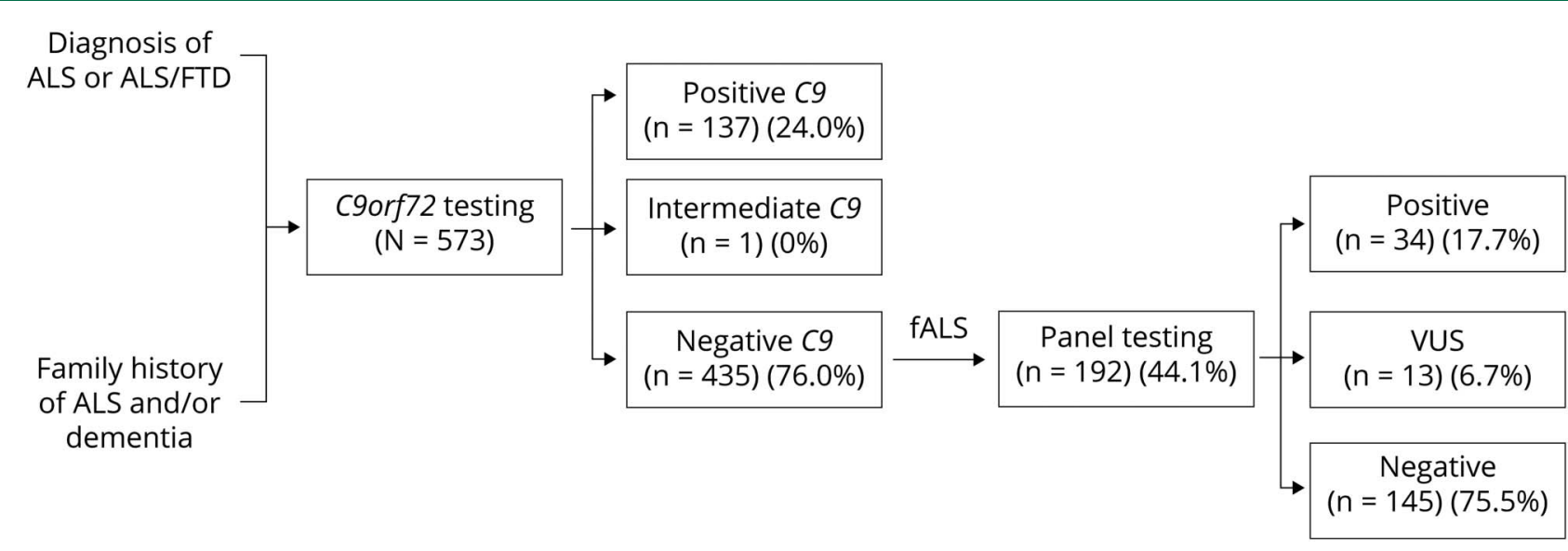

Testing schematic for the ALS Genetic Access Program. Positive C9orf72 HRE is defined as $>30$ hexanucleotide repeats in the C9orf72 gene, intermediate C9orf72 HRE is defined as 25-29 repeats, and negative C9orf72 HRE is defined as $<25$ repeats. Only patients with a fALS (with or without a family history of dementia) were offered panel testing. $A L S=$ amyotrophic lateral sclerosis; $f A L S=$ family history of ALS; FTD = frontotemporal dementia; HRE = hexanucleotide repeat expansion; VUS = variants of uncertain significance.

affected SDR and 1 affected TDR $=3$. Dementia family history was not scored.

\section{Statistical Analysis}

Descriptive statistics were used to summarize demographic and clinical characteristics, as well as testing outcomes, overall and by relevant subgroups (e.g., ALS, ALS/FTD, fALS, dALS, fALS/dALS, geoancestry, and age at onset). Because of the small number of participants who did not report European geoancestry, participants were grouped as Caucasian and non-Caucasian for the purposes of this analysis.

Comparisons between testing outcomes and subgroups were assessed using descriptive statistics as well as $\chi^{2} /$ Fisher exact tests or analysis of variance, where appropriate. Logistic regression models were used to produce odds ratios (ORs) to evaluate the impact of early-onset ALS and family history on test outcome. Statistical analysis was performed using SAS/ STAT statistical software (version 9.4 of SAS for Windows; SAS Institute Inc, Cary, NC).

\section{Data Availability}

All data are included in supplementary files (links.lww.com/ NXG/A441).

\section{Results}

\section{Cohort Demographics}

The tested cohort comprised 573 patients with ALS or ALS/FTD. Tested individuals had a diagnosis of either ALS alone $(n=490)$ or ALS and concomitant FTD $(n=$ 83). Across the cohort as a whole, mean age at disease onset was 58.2 years (range 22-85 years), and mean age at genetic testing was 61 years (range $22-88$ years). Onset of disease occurred earlier in those diagnosed with ALS alone (mean age at diagnosis 57.4 years) compared with those diagnosed with ALS/FTD (mean age at diagnosis 64.5 years; $p<0.001$; eTable 1, links.lww.com/NXG/A441).

Patients from more than 100 NEALS clinics across the United States were tested in the program. Geographic representation was greatest from the south $(180 / 573,31.4 \%)$ followed by the Midwest $(155 / 573 ; 27.1 \%)$, the west $(122 / 573 ; 21.29 \%)$, and the northeast $(76 / 573 ; 13.26 \%)$. For 40 patients $(7.0 \%)$, clinic location was not provided.

The majority of patients with ALS in our cohort reported European geoancestry $(360 / 573 ; 62.8 \%)$ followed by African American or African $(21 / 573 ; 3.7 \%)$ and Asian/Native American $(6 / 573 ; 1.0 \%)$. Geoancestry was unknown or not reported in $32.5 \%(186 / 573)$ of the cohort. This distribution was similar among those with ALS alone and ALS/FTD (eTable 1, links.lww.com/NXG/A441). The proportion of ancestry representation was not found to differ between geographic regions.

\section{Genetic Diagnosis Identified in $30 \%$ of Program Participants}

Approximately 1 in 3 program participants received a positive genetic diagnosis (171/573, 30.0\%; Figure $2 \mathrm{~A})$, either testing positive for a C9orf72 HRE $(137 / 573 ; 24.0 \%)$ or testing positive for a P or LP variant in 1 of the 5 panel genes (34/573; 6.0\%). Variants of uncertain significance (VUS) were identified in $2.4 \%$ of all program participants (14/573) and in $6.7 \%$ of patients with fALS and fALS/dALS who initially tested negative for C9orf72 HRE (13/192). Only 1 intermediate C9orf72 HRE was identified in the cohort $(1 / 573 ; 0.2 \%)$. The distribution of positive, negative, and uncertain test outcomes by clinical diagnosis and family history type is depicted in Figure 2A. 


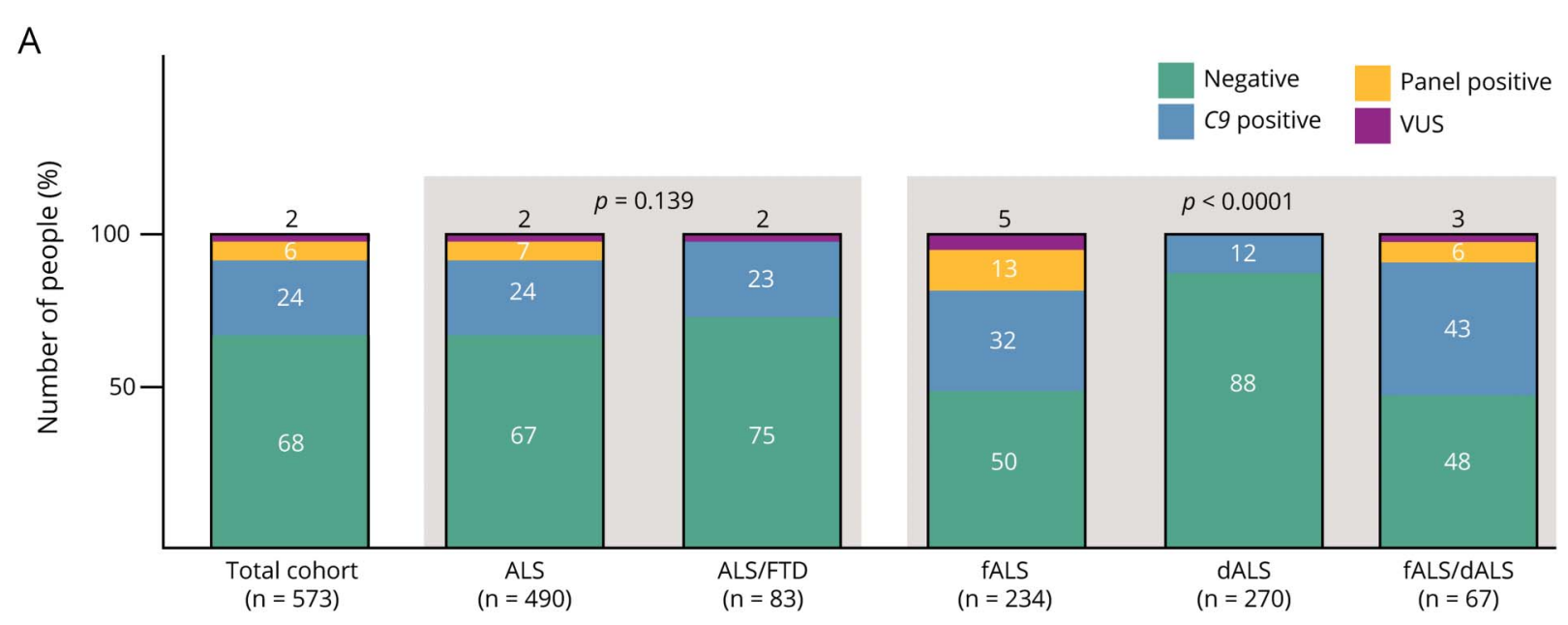

B
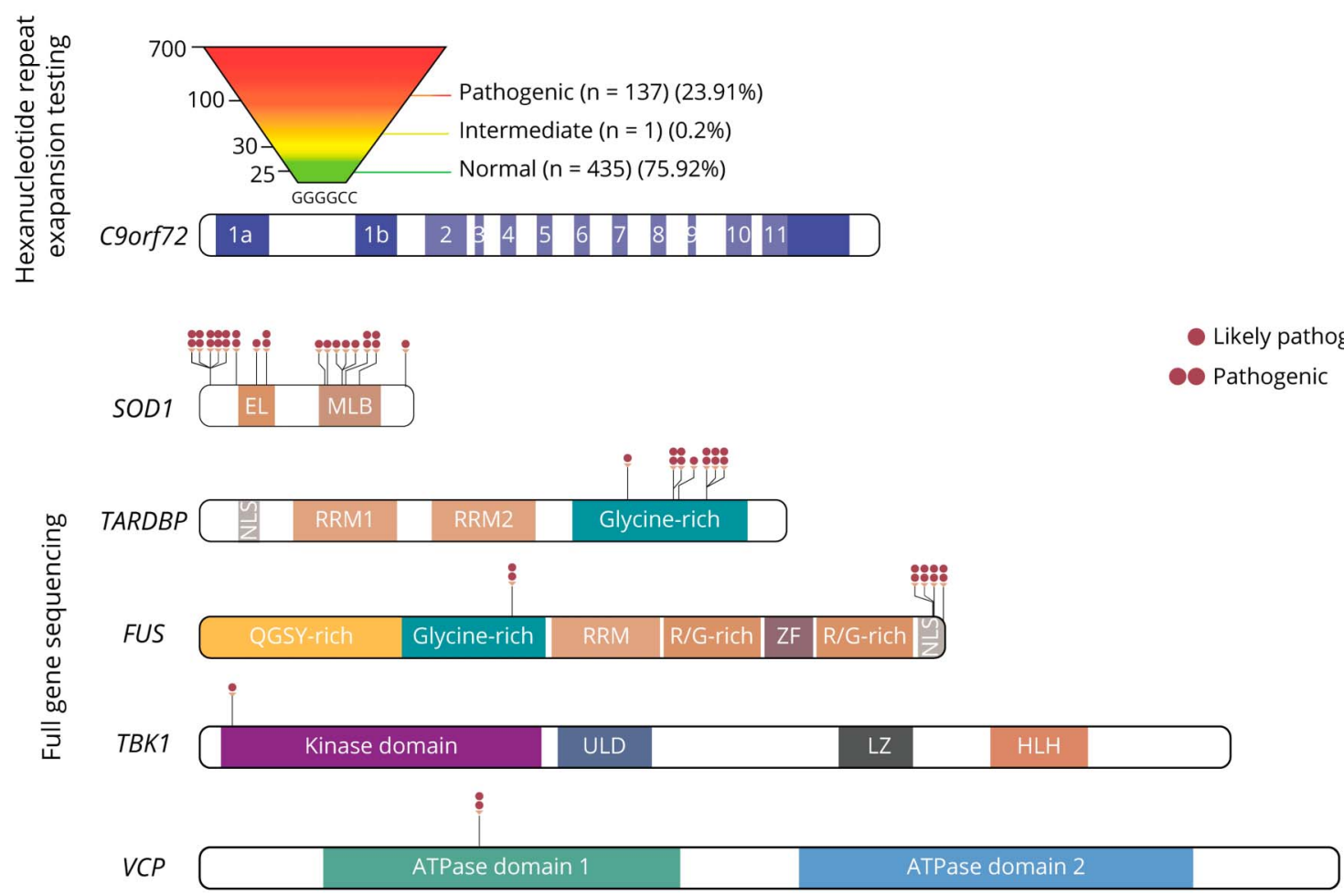

(A) Testing outcomes stratified by diagnosis and family history. (B) Pathogenic and likely pathogenic variants identified via C9orf72 HRE and targeted panel testing. Only patients with fALS or fALS/dALS were offered panel testing. ALS = amyotrophic lateral sclerosis; dALS = patients with a family history of dementia; EL = electrostatic loop; fALS = patients with a family history of ALS; fALS/dALS = patients with a family history of ALS and dementia; FTD = frontotemporal dementia; HLH = helix-loop-helix; LZ = leucine zipper; $M B L=$ metal-binding loop; NLS = nuclear localization signal; $\mathrm{QGSY}=$ region rich in glutamine, glycine, serine and/or tyrosine; RRM = RNA recognition motif; ULD = ubiquitin-like domain; VUS = variants of uncertain significance; $\mathrm{ZF}=$ zinc finger domain.

In targeted panel testing, $\mathrm{P}$ or LP variants were identified in all 5 tested genes $(S O D 1 \mathrm{n}=19, T A R D B P \mathrm{n}=7$, FUS $\mathrm{n}=5$, $V C P \mathrm{n}=2, T B K 1 \mathrm{n}=1$; Figure 2B). After the C9orf72 HRE, $\mathrm{P}$ or LP variants in SOD1 were the second most frequent finding, and variants were distributed across the gene. In TARDBP, $\mathrm{P}$ and $\mathrm{LP}$ variants clustered in the glycine-rich domain. In FUS, $\mathrm{P}$ and LP variants clustered in the nuclear localization signal. In both TBK1 and VCP, only $1 \mathrm{P}$ or LP variant was identified.
The diagnostic yield in patients with ALS alone was similar to those with ALS/FTD (ALS 118/490, 24.1\%; ALS/FTD 19/ 83, 22.9\%, Figure 2A). No patients with ALS/FTD tested positive on panel testing, whereas 34 patients with ALS with no concomitant FTD who were negative for the C9orf $72 \mathrm{HRE}$ had a positive result on panel testing $(34 / 490 ; 6.9 \%)$.

Among the family history categories, those with fALS/dALS had the highest diagnostic yield $(33 / 67 ; 49.2 \%)$, followed by 
Table 1 Higher Likelihood of Positive Test With Earlier Disease Onset

\begin{tabular}{llll}
\hline Test outcome & Onset age interval, y & OR $(95 \% \mathrm{Cl})$ & $p$ Value \\
\hline C9orf72 HRE positive & 10 & $1.04(0.87-1.24)$ & 0.673 \\
\hline Panel positive & 10 & $1.4(1.1-1.9)$ & 0.010 \\
\hline Overall positive & 10 & $1.16(0.99-1.37)$ & 0.066 \\
\hline
\end{tabular}

Abbreviations: $\mathrm{Cl}=$ confidence interval; $\mathrm{HRE}=$ hexanucleotide repeat expansion; OR = odds ratio.

For each analysis, $\mathrm{n}=480$.

ALS only (fALS) $(105 / 234 ; 44.8 \%)$ and dementia only (dALS) $(32 / 270 ; 11.9 \%)(p<0.001$; Figure 2A). dALS cases were tested only for the C9orf72 HRE. Two patients with incomplete family history information were excluded from analysis $(\mathrm{n}=571)$.

\section{Most Participants Were Not Referred for Genetic Counseling via the Program}

Of 573 participants who underwent testing, 93 (16.2\%) were referred for genetic counseling, which was an optional component of the program. The majority of referrals (90/93; 96.8\%) were made for post-test counseling, with 2 cases referred for pretesting counseling and 1 case referred for preand post-test counseling.

\section{Those With Earlier Disease Onset and Stronger Family History More Likely to Test Positive}

To investigate the effect of age of disease onset on the likelihood of a positive test result, a logistic regression model was applied. We sought to test the effect of a 10-year age unit increase on the likelihood of a positive test (Table 1). Generally, estimates show that those who are younger at disease onset are more likely to test positive, specifically, for a panel gene (OR of younger age interval with likelihood of positive test $=1.4, p=0.01$, confidence interval $=1.1-1.9)$. Similarly, we investigated the effect of strength of ALS family history, as measured by family history score, on likelihood of positive test result. We observed that those with higher family history scores were more likely to test positive (OR $=1.72, p<$ $0.001)$.

\section{Testing Outcomes Differ by Geoancestry}

Given the different geographic frequencies of variants such as the C9orf $72 \mathrm{HRE}$, we also compared test outcomes in individuals for whom geoancestry was reported $(\mathrm{n}=396$; Table 2). Because of the small number of participants who did not report European geoancestry, cases were grouped as Caucasian and non-Caucasian for the purposes of this analysis. Between Caucasians and non-Caucasians, the rates of positive, uncertain, and negative test outcomes were similar. However, significantly more Caucasian patients tested positive for C9orf $72 \mathrm{HRE}$ than non-Caucasian patients (84/357; $23.5 \%$ vs $5 / 36 ; 12.8 \%$, respectively; $p=0.028)$. NonCaucasians had a greater proportion of positive results on panel testing, although this was not significant, possibly due to small numbers in this comparison. Of interest, the 5 nonCaucasian patients with ALS who tested positive on the panel were all Black or Latino persons identified with SOD1 variants.

\section{Discussion}

Previous research has shown that patients with ALS desire access to and value genetic testing. ${ }^{9,10}$ However, genetic testing is not standard of care, and testing practices vary widely. ${ }^{11}$ The ALS GAP program was designed as pilot clinical testing and counseling service for patients cared for at NEALS-member clinics. This program addresses several current barriers to testing access including cost, identifying appropriate candidates for testing, appropriate test selection, and access to genetic counseling; it provides a model for the widespread application of ALS genetic testing in the clinic.

To optimize program funding for the identification of genetic cases, our testing approach relied on family history criteria and a targeted, 5 gene sequencing panel for familial cases. The diagnostic yield in familial cases, $45.8 \%$ (138/301), is somewhat lower than that of other recently reported clinic-based ALS testing programs, which ranged from $56.0 \%$ in a US ${ }^{12}$ to $66.7 \%$ in an Italian cohort. ${ }^{13}$ Although larger panels were used in these cohorts, the higher diagnostic yields in those reports are not attributable to a greater number of genes tested because nearly all P and LP variants were identified in the same 6 genes tested in our program. Possible explanations for the lower diagnostic yield in our cohort include more stringent application of ACMG variant interpretation guidelines, as well as the possibility of clinician falsification of family history data to enable patients with no family of ALS or dementia to access testing.

Notably, the proportion of uncertain panel results (VUS) in HRE-negative fALS cases (6.8\%) is significantly lower than these previously reported cohorts, which ranged from $21.4 \%,{ }^{13}$ to $47 \%{ }^{12}$ These data reveal an additional cost to the use of a comprehensive panel: although the diagnostic yield may (or may not) be marginally higher, far more VUS are identified. This proportional relationship between the number of genes tested and VUS identified has been reported previously. ${ }^{14}$ With ALS genes in particular, options for resolving VUS may be limited. Criteria for variant pathogenicity rest on published evidence, including functional studies establishing deleterious impact as well as cosegregation with disease in multiple affected cases. ${ }^{4}$ Functional data are not available for many ALS genes, and segregation studies are often not possible because affected relatives are deceased or not available for testing. The suitability of ACMG criteria for variant interpretation in ALS genes has been questioned, and efforts are underway to refine ALS variant interpretation using disease- and gene-specific data. ${ }^{15}$ 
Table 2 Testing Outcomes Differ by Geoancestry

\begin{tabular}{|c|c|c|c|c|c|}
\hline Test & Outcome & Caucasian $(n=357), n(\%)$ & Non-Caucasian ( $\mathrm{n}=39), \mathrm{n}(\%)$ & Total $(n=396), n(\%)$ & $p$ Value \\
\hline \multirow[t]{3}{*}{ C9orf72 HRE } & Negative & $273(76.5)$ & $33(84.6)$ & $306(77.3)$ & 0.028 \\
\hline & Intermediate & $0(0.0)$ & $1(2.6)$ & $1(0.3)$ & \\
\hline & Positive & $84(23.5)$ & $5(12.8)$ & $89(22.4)$ & \\
\hline \multirow[t]{3}{*}{ Panel* } & Negative & $88(75.8)$ & $12(70.6)$ & $100(75.2)$ & 0.194 \\
\hline & Uncertain & $11(9.5)$ & $0(0.0)$ & $11(8.3)$ & \\
\hline & Positive & $17(14.7)$ & $5(29.4)$ & $22(16.5)$ & \\
\hline \multirow[t]{3}{*}{ Total } & Negative & $245(68.6)$ & $28(71.8)$ & $273(68.9)$ & 0.943 \\
\hline & Intermediate/uncertain & $11(3.1)$ & $1(2.6)$ & $12(3.0)$ & \\
\hline & Positive & $101(28.3)$ & $10(25.6)$ & $111(28.1)$ & \\
\hline
\end{tabular}

* Panel testing was done in 133 patients for whom ancestry was reported.

Abbreviation: HRE = hexanucleotide repeat expansion.

Although the impact of VUS in ALS genetic testing has not been studied, the uncertainty surrounding a VUS result can be difficult for patients to understand and accurately recall, affecting risk perception and subsequent decision making. ${ }^{16-18}$ Clinician misinterpretation of VUS can be harmful to patients. ${ }^{19-21}$ However, VUS must be first identified to be eventually resolved or better understood. As ALS genetic testing is expanded to broader clinic and patient populations, the pros and cons of a targeted vs comprehensive testing panel must be weighed. Clinics that are new to genetic testing, and/or lack access to genetic counselors, may benefit from the use of a targeted panel until VUS rates decrease. An additional advantage of a targeted panel consisting of well-established, high-penetrance genes is that such genes are more likely to be targets for interventional trials. A targeted panel may therefore be suitable for patients who seek genetic testing for clinical trial eligibility.

Although all patients tested in our cohort had a dALS (qualifying for HRE testing), fALS, or fALS/dALS, (qualifying for HRE plus targeted panel testing), the relationship we observed between younger onset age and higher likelihood of a positive result supports the use of young age at onset as a criterion for the offer of genetic testing. Other studies have reported higher diagnostic yields of genetic testing in patients with earlier-onset disease compared with patients with typical onset of disease: in juvenile ALS cohorts, the yield of testing was reported as $43 \%$ in a German study ${ }^{22}$ and $31 \%$ in a Chinese study. ${ }^{23}$ Among patients with onset age $<50$ years, $18.5 \%$ tested positive for a P or LP variant in a recent clinicbased study in the United States. ${ }^{12}$ Early-onset sporadic cases may be viewed as fALS cases waiting to happen, and we suggest that they should be offered the same testing as fALS cases, particularly because they appear to be more likely to test positive for FUS or SOD1 than the C9orf72 HRE.

Our test outcomes data confirm that the C9orf $72 \mathrm{HRE}$ is by far the more frequent pathogenic ALS variant identified in clinical practice in the United States. Notably, the C9orf 72 HRE accounted for all positive outcomes in the ALS/FTD cohort $(19 / 83$; 22.9\%), indicating that other P and LP variants are rare in this group. Variants in SOD1, the second most frequent genetic cause of ALS in the cohort, do not cause dementia. ${ }^{24}$ Although Caucasian patients with ALS are significantly more likely to test positive for the HRE, patients of other geoancestry may be more likely to test positive for other genes such as SOD1. These data may contribute to the development of geoancestry-specific testing approaches in the future. Further study is needed on the genetic profile of ALS in patients of diverse geoancestry.

Despite the availability of free genetic counseling for all program participants, only $16.2 \%$ of participants were referred by their clinician. Possible explanations for the low utilization of this service include clinician uncertainty regarding the referral process, clinician confidence with providing genetic counseling themselves, unfamiliarity or lack of confidence with the telemedicine genetic counselors, the low VUS rate in the test outcomes, and patient lack of interest in genetic counseling. Unfortunately, we were not able to collect data to investigate these issues, and further study is needed regarding the uptake and utility of genetic counseling in ALS.

Finally, this program contributes useful data to questions of resource allocation in genetic testing. In limiting program participation to those patients at highest risk for genetic etiology (those with dALS, fALS, or fALS/dALS), we achieved a lower per-diagnosis cost than if all persons with ALS were offered testing, irrespective of family history. We obtained further savings by limiting the use of targeted panel testing to fALS cases that tested negative for the C9orf72 HRE. The per-diagnosis cost of our reflex testing approach for fALS cases was $\$ 1,304.86$ per positive diagnosis ((109 patients $\times \$ 190$ for C9orf72 HRE testing) + (192 patients $\times \$ 830$ for C9orf72 HRE testing with reflex to 
targeted panel testing) $=\$ 180,070$ to identify 138 positives). Had C9orf72 HRE and targeted panel testing been performed in every fALS participant, the per-diagnosis cost would be $\$ 1,810.36$. Double variant carriers harboring both the C9orf $72 \mathrm{HRE}$ and an additional pathogenic variant are very rare. ${ }^{25}$ Other genetic testing programs, whether funded by insurers, researchers, or health care systems, may wish to consider the value of prioritizing high-risk patients and reflex testing strategies to reduce the per-diagnosis cost of testing.

The participant and test outcomes data reported here rely on clinician report of all clinical data, including participant diagnosis, age at onset, family history, and geoancestry. Given that this program provided testing free of charge to patients, some clinicians may have falsified family history or other data to provide patients with access to testing. However, the expected effect of this bias would be to decrease, not increase, reported diagnostic yields. Patients of lower socioeconomic status may be overrepresented in the cohort, given that clinicians were encouraged to prioritize patients with limited resources for participation.

The ALS GAP program represents the largest ALS cohort ever to undergo clinical genetic testing for ALS using standard testing and interpretation criteria. In this cohort, approximately 1 in 3 program participants received a positive genetic diagnosis. In addition, the use of a small, targeted gene panel resulted in low rate of uncertain test outcomes that are problematic in clinical practice. This program serves as a successful model for the practice of genetic testing in the ALS clinic, and our test outcomes data may serve to inform testing practice guidelines, clinical trial design, and genetic counseling for persons with ALS.

\section{Acknowledgment}

Statistical analysis and graphic illustration support for this study was provided by the Ohio State University Neuroscience Research Institute and Ohio State University Biomedical Illustration, respectively.

\section{Study Funding}

The ALS GAP program was funded by grants to NEALS from the ALS Association, the Muscular Dystrophy Association, Biogen, and AveXis.

\section{Disclosure}

J. Roggenbuck., K.A. Rich., L. Vicini, T. Lincoln, and J.D. Glass report no disclosures relevant to the manuscript. J. Schroeder, C. Zaleski, and L. Drury are employees of Prevention Genetics, LLC. Go to Neurology.org/NG for full disclosures.

\section{Publication History}

Received by Neurology: Genetics February 10, 2021. Accepted in final form May 20, 2021.

\section{Appendix Authors}

\begin{tabular}{lll}
\hline Name & Location & Contribution \\
\hline $\begin{array}{l}\text { Jennifer } \\
\text { Roggenbuck, } \\
\text { MS, CGC }\end{array}$ & $\begin{array}{l}\text { The Ohio State University } \\
\text { Columbus }\end{array}$ & $\begin{array}{l}\text { Drafting/revision of the } \\
\text { manuscript for content, }\end{array}$ \\
& $\begin{array}{l}\text { including medical writing for } \\
\text { content; major role in the } \\
\text { acquisition of data; study } \\
\text { concept or design; and } \\
\text { analysis or interpretation of } \\
\text { data }\end{array}$ \\
\end{tabular}

\begin{tabular}{lll}
\hline Kelly A. Rich, & The Ohio State University & $\begin{array}{l}\text { Drafting/revision of the } \\
\text { manuscript for content, }\end{array}$ \\
MS, CGC & $\begin{array}{l}\text { Wexner Medical Center, } \\
\text { Columbus }\end{array}$ & $\begin{array}{l}\text { including medical writing for } \\
\text { content, and analysis or } \\
\text { interpretation of data }\end{array}$
\end{tabular}

\begin{tabular}{|c|c|c|}
\hline $\begin{array}{l}\text { Leah Vicini, } \\
\text { MS, CGC }\end{array}$ & $\begin{array}{l}\text { The Ohio State University } \\
\text { Wexner Medical Center, } \\
\text { College of Medicine, } \\
\text { Columbus }\end{array}$ & $\begin{array}{l}\text { Analysis or interpretation of } \\
\text { data }\end{array}$ \\
\hline $\begin{array}{l}\text { Marilly } \\
\text { Palettas, } \\
\text { MPH }\end{array}$ & $\begin{array}{l}\text { The Ohio State University, } \\
\text { Center for Biostatistics, } \\
\text { Columbus }\end{array}$ & $\begin{array}{l}\text { Analysis or interpretation of } \\
\text { data }\end{array}$ \\
\hline $\begin{array}{l}\text { Joceyln } \\
\text { Schroeder, } \\
\text { BS }\end{array}$ & $\begin{array}{l}\text { PreventionGenetics, LLC, } \\
\text { Marshfield, WI }\end{array}$ & $\begin{array}{l}\text { Study concept or design and } \\
\text { analysis or interpretation of } \\
\text { data }\end{array}$ \\
\hline $\begin{array}{l}\text { Christina } \\
\text { Zaleski, MS, } \\
\text { CGC }\end{array}$ & $\begin{array}{l}\text { PreventionGenetics, LLC, } \\
\text { Marshfield, WI }\end{array}$ & $\begin{array}{l}\text { Analysis or interpretation of } \\
\text { data }\end{array}$ \\
\hline $\begin{array}{l}\text { Tara Lincoln, } \\
\text { MLIS }\end{array}$ & $\begin{array}{l}\text { PreventionGenetics, LLC, } \\
\text { Marshfield, WI; The } \\
\text { Northeast ALS Consortium } \\
\text { (NEALS) }\end{array}$ & Study concept or design \\
\hline $\begin{array}{l}\text { Luke Drury, } \\
\text { PhD }\end{array}$ & $\begin{array}{l}\text { PreventionGenetics, LLC, } \\
\text { Marshfield, WI }\end{array}$ & $\begin{array}{l}\text { Drafting/revision of the } \\
\text { manuscript for content, } \\
\text { including medical writing for } \\
\text { content, and analysis or } \\
\text { interpretation of data }\end{array}$ \\
\hline $\begin{array}{l}\text { Jonathan D. } \\
\text { Glass, MD }\end{array}$ & $\begin{array}{l}\text { Emory ALS Center, Emory } \\
\text { University School of } \\
\text { Medicine, Atlanta, GA }\end{array}$ & $\begin{array}{l}\text { Drafting/revision of the } \\
\text { manuscript for content, } \\
\text { including medical writing for } \\
\text { content; major role in the } \\
\text { acquisition of data; study } \\
\text { concept or design; and } \\
\text { analysis or interpretation of } \\
\text { data. }\end{array}$ \\
\hline
\end{tabular}

\section{References}

1. Andersen PM, Borasio GD, Dengler R, et al. EFNS task force on management of amyotrophic lateral sclerosis: guidelines for diagnosing and clinical care of patients and relatives. Eur J Neurol. 2005;12(12):921-938.

2. Miller RG, Jackson CE, Kasarskis EJ, et al. Practice parameter update: the care of the patient with amyotrophic lateral sclerosis: multidisciplinary care, symptom management, and cognitive/behavioral impairment (an evidence-based review): report of the Quality Standards Subcommittee of the American Academy of Neurology. Neurology. 2009; 73(15):1227-1233.

3. Roggenbuck J. C9orf72 and the care of the patient with ALS or FTD: progress and recommendations after 10 years. Neurol Genet. 2021;7(1):e542.

4. Richards S, Aziz N, Bale S, et al. Standards and guidelines for the interpretation of sequence variants: a joint consensus recommendation of the American College of Medical Genetics and Genomics and the Association for Molecular Pathology. Genet Med. 2015;17(5):405-424.

5. Umoh ME, Fournier C, Li Y, et al. Comparative analysis of C9orf72 and sporadic disease in an ALS clinic population. Neurology. 2016;87(10):1024-1030.

6. Renton AE, Chiò A, Traynor BJ. State of play in amyotrophic lateral sclerosis genetics. Nat Neurosci. 2014;17(1):17-23.

7. Chia R, Chiò A, Traynor BJ. Novel genes associated with amyotrophic lateral sclerosis: diagnostic and clinical implications. Lancet Neurol. 2018;17(1):94-102. 
8. Church JM. A scoring system for the strength of a family history of colorectal cancer. Dis Colon Rectum. 2005;48(5):889-896.

9. Wagner KN, Nagaraja HN, Allain DC, Quick A, Kolb SJ, Roggenbuck J. Patients with sporadic and familial amyotrophic lateral sclerosis found value in genetic testing. Mol Genet Genomic Med. 2018;6(2):224-229.

10. Wagner KN, Nagaraja H, Allain DC, Quick A, Kolb S, Roggenbuck J. Patients with amyotrophic lateral sclerosis have high interest in and limited access to genetic testing. J Genet Couns. 2017;26(3):604-611.

11. Klepek H, Nagaraja H, Goutman SA, Quick A, Kolb SJ, Roggenbuck J. Lack of consensus in ALS genetic testing practices and divergent views between ALS clinicians and patients. Amyotroph Lateral Scler Frontotemporal Degener. 2019;20(3-4):216-221.

12. Roggenbuck J, Palettas M, Vicini L, Patel R, Quick A, Kolb SJ. Incidence of pathogenic, likely pathogenic, and uncertain ALS variants in a clinic cohort. Neurol Genet. 2020;6(1):e390.

13. Lattante S, Marangi G, Doronzio PN, et al. High-throughput genetic testing in ALS: the challenging path of variant classification considering the ACMG guidelines. Genes. 2020;11(10):1123.

14. Shirts BH, Pritchard CC, Walsh T. Family-specific variants and the limits of human genetics. Trends Mol Med. 2016;22(11):925-934.

15. Leighton D, de Araujo Martins Moreno C, Lehrer H, et al. Assessing ACMG criteria for the classification of reported ALS gene mutations: utility, pitfalls and recommendations. Neurology. 2019;92(15 suppl).

16. Vos J, Otten W, van Asperen C, Jansen A, Menko F, Tibben A. The counsellees' view of an unclassified variant in BRCA1/2: recall, interpretation, and impact on life. Psychooncology. 2008;17(8):822-830.
17. Culver JO, Brinkerhoff CD, Clague J, et al. Variants of uncertain significance in BRCA testing: evaluation of surgical decisions, risk perception, and cancer distress. Clin Genet. 2013;84(5):464-472.

18. Murray ML, Cerrato F, Bennett RL, Jarvik GP. Follow-up of carriers of BRCA1 and BRCA2 variants of unknown significance: variant reclassification and surgical decisions. Genet Med. 2011;13(12):998-1005

19. Makhnoon S, Garrett LT, Burke W, Bowen DJ, Shirts BH. Experiences of patients seeking to participate in variant of uncertain significance reclassification research. J Community Genet. 2019;10(2):189-196.

20. O'Neill SC, Rini C, Goldsmith RE, Valdimarsdottir H, Cohen LH, Schwartz MD Distress among women receiving uninformative BRCA1/2 results: 12-month outcomes. Psychooncology. 2009;18(10):1088-1096.

21. van Dijk S, Timmermans DRM, Meijers-Heijboer H, Tibben A, van Asperen CJ, Otten W. Clinical characteristics affect the impact of an uninformative DNA tes result: the course of worry and distress experienced by women who apply for genetic testing for breast cancer. J Clin Oncol. 2006;24(22):3672-3677.

22. Hübers A, Just W, Rosenbohm A, et al. De novo FUS mutations are the most frequent genetic cause in early-onset German ALS patients. Neurobiol Aging. 2015;36(11):3117.e1-3117.e6.

23. Zou Z-Y, Liu M-S, Li X-G, Cui L-Y. Mutations in FUS are the most frequent genetic cause in juvenile sporadic ALS patients of Chinese origin. Amyotroph Lateral Scler Frontotemporal Degener. 2016;17(3-4):249-252.

24. Wicks P, Abrahams S, Papps B, et al. SOD1 and cognitive dysfunction in familial amyotrophic lateral sclerosis. J Neurol. 2009;256(2):234-241.

25. Ross JP, Leblond CS, Laurent SB, et al. Oligogenicity, C9orf72 expansion, and variant severity in ALS. Neurogenetics. 2020;21(3):227-242. 


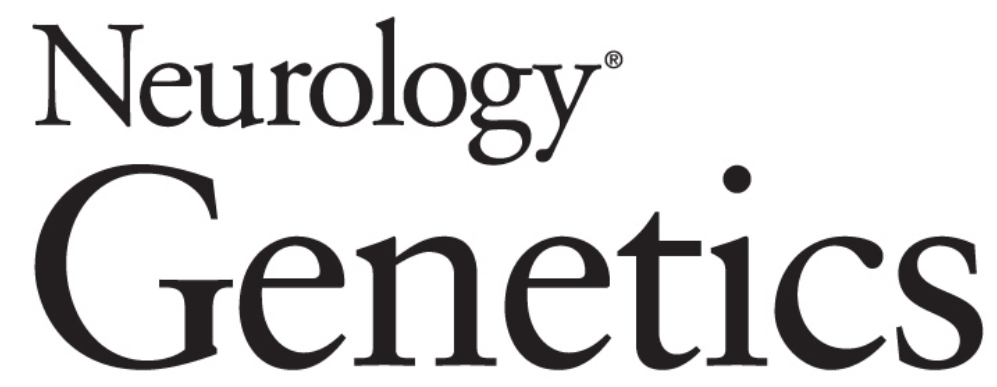

Amyotrophic Lateral Sclerosis Genetic Access Program: Paving the Way for Genetic Characterization of ALS in the Clinic

Jennifer Roggenbuck, Kelly A. Rich, Leah Vicini, et al. Neurol Genet 2021;7;

DOI 10.1212/NXG.0000000000000615

This information is current as of August 10, 2021

Neurol Genet is an official journal of the American Academy of Neurology. Published since April 2015, it is an open-access, online-only, continuous publication journal. Copyright Copyright ( 2021 The Author(s). Published by Wolters Kluwer Health, Inc. on behalf of the American Academy of Neurology.. All rights reserved. Online ISSN: 2376-7839.

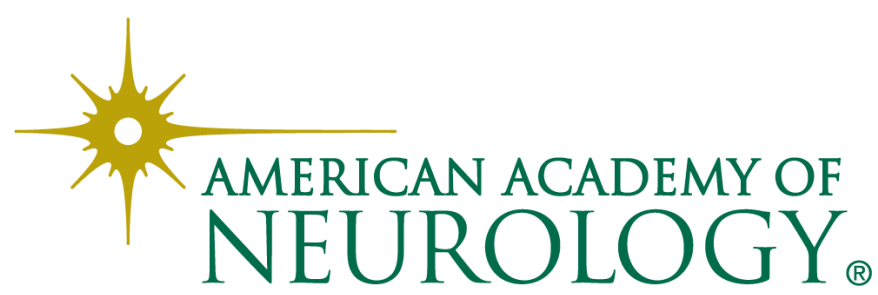




\section{Updated Information \& Services}

References

Citations

Subspecialty Collections

Permissions \& Licensing

Reprints including high resolution figures, can be found at: http://ng.neurology.org/content/7/5/e615.full.html

This article cites 24 articles, 3 of which you can access for free at: http://ng.neurology.org/content/7/5/e615.full.html\#\#ref-list-1

This article has been cited by 2 HighWire-hosted articles: http://ng.neurology.org/content/7/5/e615.full.html\#\#otherarticles

This article, along with others on similar topics, appears in the following collection(s):

\section{All Genetics}

http://ng.neurology.org//cgi/collection/all_genetics Amyotrophic lateral sclerosis

http://ng.neurology.org//cgi/collection/amyotrophic_lateral_sclerosis_ Frontotemporal dementia http://ng.neurology.org//cgi/collection/frontotemporal_dementia

Information about reproducing this article in parts (figures,tables) or in its entirety can be found online at:

http://ng.neurology.org/misc/about.xhtml\#permissions

Information about ordering reprints can be found online: http://ng.neurology.org/misc/addir.xhtml\#reprintsus

Neurol Genet is an official journal of the American Academy of Neurology. Published since April 2015, it is an open-access, online-only, continuous publication journal. Copyright Copyright $\odot 2021$ The Author(s). Published by Wolters Kluwer Health, Inc. on behalf of the American Academy of Neurology.. All rights reserved. Online ISSN: 2376-7839.

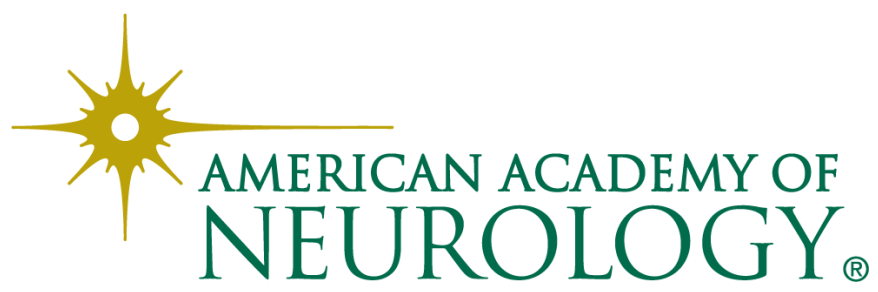

